\title{
Research on the Development of Intelligent Transportation Based on Smart City
}

\author{
Yawen Tang, Yuhan Xiong*, Wan Yu, Chuyun Tian and Zhengde Bao \\ Jincheng College of Sichuan University, No.1, Xi-yuan Road, West High-tech Zone, Chengdu City, Sichuan Province, China \\ *Corresponding author
}

\begin{abstract}
With the progress of human society during the 21st century, the continuous innovation and development of networking, digitization, intelligence, information and automation have promoted the emergence of smart cities. At present, China is in an essential period of new urbanization and the rapid development of green and ecological cities. However, cities will carry more and more people in the future. The increasingly problem of "urban diseases" will inevitably lead to a series of problems in urban life. In order to solve the troubles of urban development and realize the sustainable development of cities, the construction of smart cities has become an irreversible trend in the development of cities in the world. Traffic construction has become a significant part of smart city construction. In the meantime, it has triggered the emergence of the concept of "smart transportation". We have a heated discussion about how to establish a highly efficient, safe, convenient, environmentally friendly, comfortable, economical transportation and transportation system. The improve of the smart transportation system can provide people with more smooth travel and sustainable economic development services. In the future, smart cities will run through the entire world. This article takes smart transportation for instance to discuss the present situation and the achievements of smart cities in China. In the meantime, the passage outlines the prospects of smart transportation in China.
\end{abstract}

Keywords—smart traffic; smart city; internet of things; internet of vehicle

\section{INTRODUCTION}

With the tremendous development of information technology and the rapid growth of the Internet of things, a series of advanced urban forms have emerged, such as perception cities, digital cities, wireless cities and smart cities, but smart cities are different from traditional advanced cities. A smart city is not only a smart city. However, it focuses on the intelligence of the city. What stands out is the interaction between things and things, people and things, people and people. At the same time, it reflects the perfect combination of the wisdom of mankind and things.[1]Its essence is to use advanced information and communication technologies to sense, collect, process, and analyze the operational information and key data of all parts of the city system, so as to make the system more intelligent, more efficient and more desirable for the various needs of the residents' lives. Nevertheless, the transportation system is an essential part of a smart city. It is necessary to build smart transportation at first. According to the official statistics, in the past 10 years, the level of urbanization in China has increased from 36\% in 2000 to $49.68 \%$ in 2010.
The urbanization rate in China has steadily increased to $57.35 \%$.[2]With the acceleration of the urbanization process, the ordinary traffic system can no longer carry the fast population growth, so It is urgent for us to solve a series of traffic problems such as traffic jams, traffic safety, traffic noise, and traffic environment. Smart transport is an- important ways to comprehensively deepen reforms in the transportation sector. In the meantime, it is a breakthrough in solving existing traffic problems.

\section{THE BACKGROUND OF SMART CITY AND SMART TRAFFIC}

\section{A. The Great Base of China's Urban Center Growing Rapidly}

China is the world's most populous country. The growth of population in urban centers, the increasing demand for energy efficiency, inter-city investment competition, and other demand from people are making cities' systems more stressful. The contradiction between population growth and urban development is increasingly highlighted. In order to balance the problems of population and urban development, achieving sustainable urban development and building smart transportation are urgently needed.

\section{B. Three Driving Forces Contribute to Building Smart City}

First and foremost, a new generation of advanced information technologies represented by the fast development of the Internet of Things, cloud computing, artificial intelligence and so on. Besides, the trend of model innovation and the life of resident tend to be highly efficient. In addition, the guidance of the national policy, encouraging Innovation and structural upgrades. These three driving force shave guided society from a technical, social and policy perspective to spontaneous development toward smart cities. Building smart transportation is one of the effective forms of practice.

\section{The Leadership of the Fourth Industrial Revolution}

Represented by the industrialization of the Internet, industrial intelligence, and industrial integration; the brand-new technological revolution based on artificial intelligence, clean energy, unmanned control technology, quantum information technology, virtual reality, and biotechnology is regarded as the fourth industry.[3]All countries have seized the height of the industry in this process. Building a smart city is the core part of the process. It is not only the gate of innovative thoughts, but 
also a catalyst for the quick development of science and social economy. If China wants to go further in the wave of the fourth industrial revolution, it must step up the construction of major smart systems such as smart transportation.

\section{THE CURRENT STATUS OF SMART TRANSPORTATION}

The report of the Nineteenth Congress put forward the great goal of building a "powerful country with a strong traffic" and required that the speed of informationization and intelligentization of expressways in China must be strengthened and speed up the construction of smart transportation. At the same time, China has invested a lot of funds in transportation and infrastructure. According to the statistics of the China Intelligent Transport Association, in 2016, China completed an investment of 17976 billion yuan in highway construction. Among them, the completion of highway construction investment 8235 billion yuan, China's new highway intelligent system market size reached 173 billion yuan, more than five years ago almost doubled the scale.[4]Currently, the mileage of high-speed rail, expressway, and city roads is respectively 25000 kilometers, 130000 kilometers and 4 million kilometers ranking first in the world. China has a natural and absolutely leading basic advantage in the field of smart traffic development. For the moment, in addition to the promotion of infrastructure, it is also providing the plan of smart transportation in various industries such as:

Smart Bus: The solution of smart bus promotes standardization of urban public traffic management, automation of operation supervision, scientific support for decision-making, rationalization of operational scheduling and the integration of information services through using various technologies such as GPS/BD satellite positioning, wireless communications, geographic information, networks, computers, automatic control and software. The solution have improved the level of urban public transport services and management, and also fully enhanced the attractiveness of urban public transport, allowing citizens to travel more safely, conveniently and environmentally.

Smart Corporate Car: In response to the national official car reform policy and combine with the concept of "Internet plus", the company launched the solution of "Internet plus" official car. The solution is based on the Internet of Things technology to create a bus operation monitoring system and intelligent deployment system so as to realize the effective supervision and the proper use of buses.

Smart School Bus: By using the Internet of Things, artificial intelligence and video surveillance, we can achieve vehicle monitoring, operation monitoring, and intelligent warning so as to ensure the effective management of such vehicles with high safety requirements.

Smart Traffic Lights: Using information technology such as artificial intelligence, big data and cloud computing to collect and analyze traffic data to achieve highly efficient, highlyreasonable, high-quality traffic planning.

ETC: Refers to the highway electronic toll collection system, which has already achieved networking in dozens of provinces and cities nationwide. The ETC in China has become one of the three major ETC technology systems with independent intellectual property rights. According to the assessment, ETC can improve the vehicle passing capacity by more than 4 times, it will effectively alleviate traffic congestion, achieve significant energy saving and emission reduction effects.[5]

Smart subway: Through the access of information technology such as artificial intelligence, cloud computing, big data and mobile payments, passengers can experience various kinds of biometric technologies such as face recognition to pass through the card, pay for the money after getting on the train. It is more convenient for passengers to enjoy subway travel.

\section{THE DEVELOPMENT OF SMART CITY}

In 2016, in Hangzhou, the ET city brain took over the 128 signal light intersections in Hangzhou, reducing the average traffic time of the pilot areas by $15.3 \%$, and the average time for the elevated road vehicles to save 4.6 minutes. Through the real-time control of the traffic light, 120 emergency vehicles such as ambulances will have to cut half of their time to the scene, hoping for more possibilities.

In 2017, baidu took the lead in signing an agreement with the Xiong'an new district government to implement pilots for smart transportation and build smart transportation templates for China and even the world.

In 2018, Alibaba's "ET City Brain" was integrated with Malaysia's localization and applied to Malaysia's traffic management, urban planning, environmental protection and other fields. In the first phase, it will be applied to 281 road junctions in the capital, Kuala Lumpur. Through the dynamic adjustment of traffic lights and traffic, accident detection and other traffic conditions to ease congestion.

\section{THE PROSPECTS OF SMART TRANSPORTATION}

Smart transportation is the forerunner of smart cities. Traffic is the core of urban infrastructure construction. The importance of its development and innovation is self-evident. The importance of transportation to the city is equal to the importance of blood vessels to people. It shoulders the role of sharing people flow, transmitting information, reducing traffic pressure and protecting the environment. The level of operational efficiency determines the overall efficiency of the city. Because of this, many scholars have spared no effort to find the theoretical basis for building a smart transportation system, and continue to innovate and improve the smart transportation system. Although the construction of smart transportation has achieved initial success, smart transportation still has enormous potential for development. After solving the current difficulties, the speed of development and the tremendous results it brings to society are unimaginable.

\section{A. Building A Smart Traffic Network}

Combining urban transportation networks with advanced intelligent transportation devices, it will also apply advanced technologies such as mobile communications, sensors and cloud computing to create a smart city traffic network. 
Realizing the real-time interconnection of roads and vehicles, vehicles and vehicles, fully guaranteeing traffic safety. The application of intelligent devices such as intelligent monitoring systems, intelligent flow observation systems and real-time road condition information systems can greatly improve the efficiency of transportation.

\section{B. Building A Smart Citizen Comprehensive Travel Service Platform}

Through this platform, the public can enjoy a convenient, quick and simple travel experience. With the help of Internet technology, resources such as ticketing system information, map information, traffic flow information and travel information are all integrated, and citizens can obtain targeted information from them to achieve a one-stop service for citizens to travel.

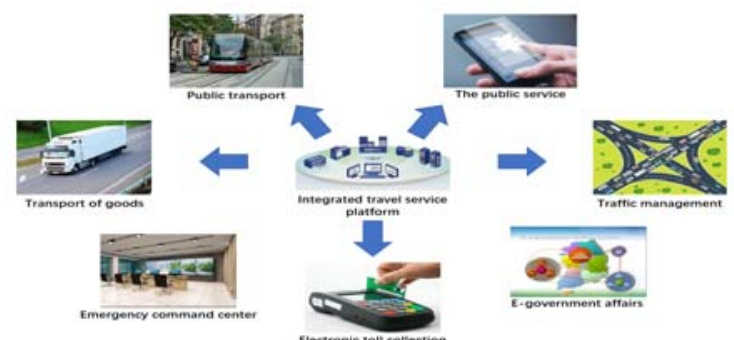

FIGURE I.

INTELLIGENT TRAFFIC EMERGENCY COMMAND AND DIS PATCH SYSTEM

\section{Building An Intelligent Traffic Emergency Command and Dispatch System}

The use of intelligent monitoring system to observe traffic conditions in real time and to predict the possible traffic accidents. Then we use the satellite positioning system to timely feedback to the scene of traffic personnel, so that they conduct the command at the scene, thus avoiding traffic accidents. If it is impossible to prevent the occurrence of an accident, we are supposed to make effective emergency decision-making in time, command and dispatch and quickly restore traffic to avoid causing major losses. At the same time, in term of rescue vehicle traffic, the system intelligently analyzes the current status of traffic and reasonably gives the rescue vehicle a "green wave".

\section{Establish A Unified Public Transport Operation Management System}

The use of this system can provide people with better planning of transportation and recommendations for transportation routes, so as to enhance the appeal of the entire public transport system and people's willingness to travel. Finally, we'll achieve the purpose of urban optimization.

\section{E. Extending Smart Transportation from Urban Infrastructure to Other Areas}

Urban basic transportation is used as the basis for smart transportation construction and expanded to other areas. For example, urban logistics ports, rail transportation, aviation and air traffic control are also included in the construction of urban smart transportation.

Creating a logistics information monitoring system and a public logistics service platform in the logistics and port areas. Establishing an integrated management system in rail transit. Building service systems integrated with ground services and airport information and air-to-air integration systems in aviation. The organic combination of basic transportation, logistics ports, rail transportation and aviation will contribute to improve the construction of smart transportation and improve the quality of smart transportation.

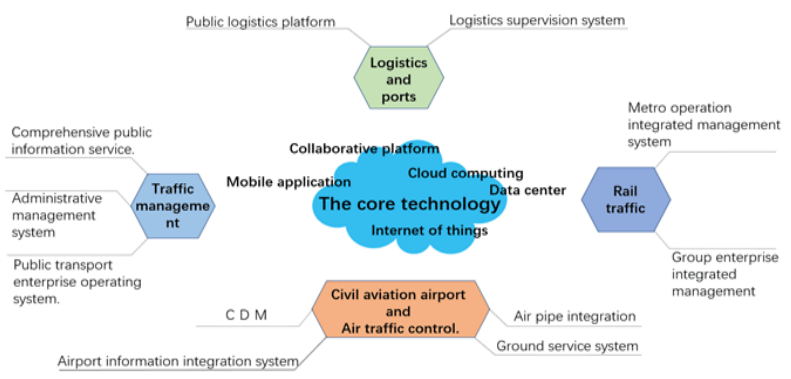

FIGURE II.

THE CORE TECHNOLOGY OF SMART TRANSPORTATION

\section{SUMMARY}

The construction of a smart city is a great project, and the smart transportation system is just a cornerstone in its construction. From the concept of smart transportation to the development of it in the several years, pilot cities for the construction of smart transportation have emerged at home and abroad. Their research focuses and directions of development are diversified: the United States seeks to achieve full connectivity of the ground transportation network; Europe is also striving to create a sustainable transportation system while focusing on environmental protection; South Korea is vigorously developing highway electronic non-stoppage Charge system, and pilot cities of smart cities in China include 290 cities such as Beijing, Shanghai, Shenzhen, Tianjin, etc.[6] Smart traffic among cities varies according to different cultures, different regions, different policies and other reasons, but based on the city's socioeconomic activities, cultural characteristics, and transportation systems to build suitable for the development of this city. The smart transportation system has become a general trend.

Technology continues to innovate and develop. The LTE-V vehicle networking plan led by Datang and Huawei is steadily advancing and seamlessly connecting to 5G. With the rise of edge computing and fog computing, in the near future, V2X and unmanned Driving is about to become a reality, and the era of truly intelligent traffic based on big data and AI technology is approaching.[7] Smart cities, as the pioneers in the construction of smart cities will also make the development of smart cities a higher level and create a better city life for human beings. 


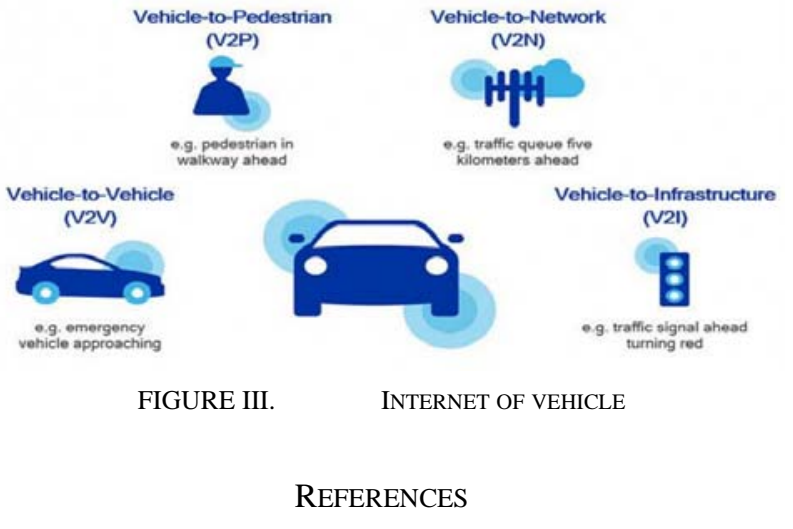

[1] Chen Gong. Application of Data Mining Technology in Smart Transportation[D]. University of Electronic Science and Technology, 2016(03)
[2] Luo Hui. Smart City and Rail Transit[C].Beijing Guo Jianxin Cultural Development Center,2015(8)

[3] Wang Keqiang. Acquisition of a new round of scientific and technological revolution China can achieve curved overtaking[J].China Strategic Emerging Industry, 2017(29)

[4] CY329.2018 Analysis of China's Smart Transportation Industry Development Trend [EB/OL]. China Industry Information Network, 2018(03)

[5] Zhiqiang Li. High-speed ETC system basically realizes nationwide network coverage in 29 provinces [EB/OL]. China Radio Network, 2015(09)

[6] Deng Yuyong, Li Wei, Liu Yang. Research on the Development of Urban Smart Transportation System in China[J].Urban, 2015(11)

[7] Kua Fu. Alibaba has quietly laid out a trillion smart transportation market [EB/OL]. Xinmin News, 2018(03)H. Goto, Y. Hasegawa, and M. Tanaka, "Efficient Scheduling Focusing on the Duality of MPL Representatives,” Proc. IEEE Symp. Computational Intelligence in Scheduling (SCIS 07), IEEE Press, Dec. 2007, pp. 57-64, doi:10.1109/SCIS.2007.357670 